\title{
Trade-off Ranking Method for Multi-Criteria Decision Analysis
}

DOI:

10.1002/mcda. 1600

Document Version

Accepted author manuscript

Link to publication record in Manchester Research Explorer

\section{Citation for published version (APA):}

Utyuzhnikov, S., \& Jaini, N. (2017). Trade-off Ranking Method for Multi-Criteria Decision Analysis. Journal of MultiCriteria Decision Analysis. https://doi.org/10.1002/mcda.1600

\section{Published in:}

Journal of Multi-Criteria Decision Analysis

\section{Citing this paper}

Please note that where the full-text provided on Manchester Research Explorer is the Author Accepted Manuscript or Proof version this may differ from the final Published version. If citing, it is advised that you check and use the publisher's definitive version.

\section{General rights}

Copyright and moral rights for the publications made accessible in the Research Explorer are retained by the authors and/or other copyright owners and it is a condition of accessing publications that users recognise and abide by the legal requirements associated with these rights.

\section{Takedown policy}

If you believe that this document breaches copyright please refer to the University of Manchester's Takedown Procedures [http://man.ac.uk/04Y6Bo] or contact uml.scholarlycommunications@manchester.ac.uk providing relevant details, so we can investigate your claim.

\section{OPEN ACCESS}




\section{Trade-off ranking method for multi-criteria decision analysis}

\section{Nor Jaini ${ }^{1}$ | Sergey Utyuzhnikov ${ }^{1,2}$}

\author{
${ }^{1}$ School of Mechanical, Aerospace and Civil \\ Engineering, The University of Manchester, \\ Manchester, M13 9PL, UK \\ 2 Moscow Institute of Physics and Technology, \\ Dolgorudny, Russia \\ Correspondence \\ Sergey Utyuzhnikov, School of Mechanical, \\ Aerospace and Civil Engineering, The \\ University of Manchester, Sackville Street, \\ Manchester, M13 9PL, UK. \\ Email: s.utyuzhnikov@manchester.ac.uk
}

\begin{abstract}
Multi-criteria decision analysis presumes trade-off between different criteria. As a result, the optimal solution is not unique and can be represented by the Pareto frontier in the objective space. Each Pareto solution is a compromise between different objectives. Despite a limited number of Pareto optimal solutions, the decision-maker eventually has to choose only one option. Such a choice has to be made with the use of additional preferences not included in the original formulation of the optimization problem. The paper represents a new approach to an automatic ranking that can help the decision-maker. In contrast to the other methodologies, the proposed method is based on the minimization of trade-off between different Pareto solutions. To be realized, the approach presumes the existence of a well-distributed Pareto set representing the entire Pareto frontier. In the paper, such a set is generated with the use of the directed search domain algorithm. The method is applied to a number of test cases and compared against two existing alternative approaches.
\end{abstract}

\section{KEYWORDS}

directed search domain algorithm, multi-criteria decision analysis, multi-objective optimization, Pareto optimal solution, trade-off, ranking

\section{1 | INTRODUCTION}

In the real-life design, it is required to improve different objectives simultaneously. A trade-off between the objectives is usually unavoidable because of the constraints. As a result, the optimal solution is not unique and corresponds to a so-called Pareto solution. In the objective space, all Pareto solutions create a Pareto frontier. For a practical decision-making analysis, the Pareto frontier is represented by a Pareto set that contains a finite number of optimal solutions. Eventually, the decision-maker has to choose only one solution. This leads to the problem of ranking because the formal definition of the Pareto solution does not presume any preferences. An additional algorithm is required to introduce the ranking.

In the multi-criteria decision analysis, the ranking problem has been developed for the last 20 years. However, there are no universal approaches. Each method stands on its own background and principles. The most natural approach is to introduce individual preferences. One of the basic and simplest multi-criteria decision analysis techniques is the sum of weightage calculation model. In this technique, a weight is assigned to each criterion to denote its importance. Each aggregate function is then calculated as the sum of weightage criteria. A classic work on the weight determination is by Eckenrode (1965). Eckenrode worked with 24 expert judges, who were required to put a weightage on six criteria in a specified experiment related to an air-defence system.

Another well-known decision-making method is the analytic hierarchy process (AHP). AHP was proposed by Saaty (1980). The essence of this method is that human judgement is used in performing evaluations. AHP structures a decision problem into a hierarchy with the goal, decision criteria, and alternatives. Then, it uses the pairwise comparison and the expert judgement, where these judgements are converted into a numerical evaluation. However, human can lack of consistency in judging (influenced by emotional, experience, and so on), and different people have different preferences. AHP works its best for decision-making process in a group of people having consensus. Many authors used AHP in the decision-making process (e.g., Kablan, (2004); Herath, (2004); Randall et al., (2004); Bascetin, (2007); Brent, Rogers, Ramabitsa-Siimane, \& Rohwer, (2007); Iwanejko, (2007); Wu, Lin, \& Chen, (2007); Srdjevic, (2007); Contreras, Hanaki, Aramaki, \& Connors, (2008); Dabaghian, Hashemi, Ebadi, \& Maknoon, (2008); Ercanoglu, Kasmer, \& Temiz, (2008); Thapa \& Murayama, (2008); Chatzimouraddis \& Pilavachi, (2009); Chen, (2009)). Current work on AHP is by Zaidan et al. (2015). They imposed the AHP method, integrated with other MCDM techniques, to select the right software for open-source electronic medical record. 
The analytic network process (ANP) is an extension of AHP also proposed by Saaty (1996). Apart of structuring the multi-objective problem as a hierarchy, ANP treats it as a network. The decision criteria in AHP assume to be independent from each another, while ANP allows interdependence of those criteria. Several authors used ANP in their research (e.g., Levy, (2005); Cheng \& Li, (2007); Banar, Kose, Ozkan, \& Acar, (2007); Khan \& Faisal, (2008); Tseng, Lin, Chiu, \& Liao, (2008); Gomez-Navarro, Garcia-Melon, Acuna-Dutra, \& Diaz-Martin, (2009); Boj, Rodriguez-Rodriguez, \& Alfaro-Saiz, (2014)).

The multi-attribute utility theory (MAUT) by Keeney and Raiffa (1976) is among the classical methods of multi-criteria decision analysis. It follows the utility axioms of von Neumann and Morgenstern. MAUT is a structured methodology designed to handle the trade-off among multiple objectives. MAUT assigns a utility value to each action and its quantifying individual's preferences. The result of using this method is a set of choices that represents the decision-maker's preferences. MAUT was employed in the decision-making by Ananda and Herath (2005).

The elimination and choice expressing reality (ELECTRE) was proposed by Bernard Roy in 1960s. ELECTRE is an outranking method that discards unacceptable alternatives and uses another multi-criteria decision-making method to select the best one. A limited set of alternatives that are obtained saves much of selecting time. Another outranking method is preference ranking organization method for enrichment evaluations (PROMETHEE), which is a modified approach of ELECTRE proposed by Brans and Vincke $P$ (1985). PROMETHEE is a much simpler version of the outranking technique that uses pairwise comparison of alternatives via a preference index. PROMETHEE consists of three tools: the PROMETHEE I (partial ranking), the PROMETHEE II (complete ranking), and the PROMETHEE-GAIA (geometrical analysis for interactive aid). Several authors applied the outranking method to multi-criteria decision problems (e.g., Goumas \& Lygerou, (2000); De Leeneer \& Pastijn, (2002); Soltanmohammadi, Osanloo, \& Bazzazi, (2009); Oberschmidt, Geldermann, Ludwig, \& Schmehl, (2010); Petrović, Bojković, Anić, Stamenković, \& Tarle, (2014)).

The genetic algorithm (GA) has also been used as a multi-criteria decision-making method. Several authors employed GA for this purpose (e.g., Fonseca \& Fleming, (1993); Tanaka, Watanabe, Furukawa, \& Tanino, (1995); Feng et al., (1997); Hegazy, (1999); Zheng, Ng, \& Kumaraswamy, (2005)). The foundation of GA lies in the survival of fitted generations that copies the process of the natural selection. Several natural selection techniques such as mutation, selection, and crossover are implemented. This approach proved to be efficient. However, in the algorithm, the solutions can bias towards some regions, and the method also produces non-Pareto solutions. The algorithm generates a large number of solutions. Eventually, most of them appear to be redundant. Massive number of solutions including redundant ones make problematic the ranking procedure.

Wang and Yang (2009) used another natural behavior algorithm, the particle swarm optimization (PSO), to determine a ranking order for the multi-criteria decision problem. The PSO was inspired by the movement of bird flock or fish school. Particle swarm improves the search ability of GA for the best alternatives by having a better convergence to the Pareto frontier. However, as shown by Wang and Yang, PSO requires up to 30,000 numbers of iterations to solve the problem. Therefore, it might be time-consuming.
The technique for order preference by similarity to the ideal solution (TOPSIS) was first proposed by Hwang and Yoon (1981). TOPSIS method embeds the priori weights that are specified beforehand by the decision-maker. The core of the ranking for this method lies in the distance of alternatives to the ideal and anti-ideal solutions. An alternative that is "closer to ideal" and "farther from anti-ideal" holds a higher ranking. However, TOPSIS produces an inconsistent ranking between the "closer to ideal" and "farther from anti-ideal." Many authors have used TOPSIS as a decision-making method (e.g., Chen, (2000); Chu \& Lin, (2003); Jahanshahloo, Lotfi, \& Izadikhah, (2006); Liu, Frazier, Kumar, MacGregor, \& Blake, (2006); Yong, (2006); Shih, Shyur, \& Lee, (2007); Wang \& Chang, (2007); Gumus, (2009); Kilic, Zaim, \& Delen, (2014)).

Kao (2010) addresses the disadvantages of inconsistency ranking in TOPSIS and proposes a consistent ranking between the "closer to ideal" and "farther from anti-ideal." In contrast to TOPSIS, Kao suggests a relative distance ranking method and introduces the posteriori weights obtained from the data. In both methods, the usage of the distance to the ideal solution as the criterion is arguable. In fact, there is no justification to the statement that the coordinate system in the objective space must be Cartesian. It is only supposed to be Cartesian for the sake of convenience.

All the existing methods consider the value of each Pareto solution separately without its position with respect to the others in the objective space. The ranking is obtained as the result of such individual evaluations. Meanwhile, any Pareto solution is a trade-off solution. It seems natural to minimize the level of trade-off to identify "the best" design. In the current paper, the ranking reflects the level of compromise between different Pareto solutions. It is clear that it is not practical and even unrealistic to consider the trade-off with all Pareto solutions. However, it is quite realistic to minimize the level of compromise for a selected Pareto set that represents the entire Pareto frontier well enough. It is worth noting that this kind of ranking is non-local because the value of each Pareto solution depends on its position with respect to the others in the objective space. In this way, the task is reduced to two problems. First, the Pareto set to be analyzed should represent the entire Pareto frontier. Second, a ranking algorithm should be identified to rearrange the Pareto set according to preferences that are beyond the original formulation of the problem. The former problem can be resolved via generating an evenly distributed Pareto set. It is well known that such a task is far from trivial. However, there are a few techniques that are able to tackle this problem such as the normal boundary intersection method (Das \& Dennis, 1998), the normal constraint method (Messac, Ismail-Yahaya, \& Mattson, (2003); Messac \& Mattson, (2004)) and the directed search domain (DSD) algorithm (Utyuzhnikov, Fantini, \& Guenov, (2005), (2009); Erfani \& Utyuzhnikov, (2011); Erfani, Utyuzhnikov, \& Kolo, (2013)). The DSD algorithm is capable of generating a well distributed Pareto set on the entire Pareto frontier in a quite general formulation. Eventually, it provides a set of limited optimal choices for the decision-maker for handling trade-off between multiple criteria.

The paper is organized as follows. The next section represents a brief introduction to the Pareto optimality. In Section 3, the main principles of the TOPSIS and the relative distance ranking method are described. The proposed algorithm of the trade-off ranking is given in Section 4. In Section 5, different test cases are considered. The conclusions are provided in the final section. 


\section{2 | PARETO OPTIMALITY}

Let the design space be presented by $X \subset R^{n}$. Consider m objective functions, forming an objective space $Y \subset R^{m}$. For each $x \in X$, there exists a point in $Y$ corresponding to mapping $R^{n} \mapsto R^{m}$.

Multi-objective optimization problem is formulated by

Minimize $Y=\left\{Y_{1}(x), Y_{2}(x), \ldots, Y_{m}(x)\right\}$,

subject tox $\in X^{*}$

Here, $X^{*} \subseteq X$ is the feasible design space defined as the set of elements $x \in X^{*}$ satisfying all the constraints. The feasible objective space $Y^{*}$ is defined as the $\operatorname{set}\left\{Y(x) \mid x \in X^{*}\right\}$.

A design vector $x \in X^{*}$ is called a Pareto optimal if there does not exist any $a \in X^{*}$ such that

$$
Y(a) \leqslant Y(x) \text { and existsk } \leqslant m: Y_{k}(a)<Y_{k}(x)
$$

\section{3 | RELATIVE DISTANCE RANKING AND TOPSIS}

In this section, the relative distance ranking and TOPSIS methods are described briefly. Both methods are used for comparison with the new proposed method as they all lead to automatic ranking that does not presume an immediate selection based on subjective experts opinion.

Both methods imply the same idea of having the alternative "closer to ideal" and "farther from anti-ideal" solution. One difference is in the calculation of the distance. The TOPSIS uses the Euclidean distance from an alternative to the ideal or anti-ideal solution that is the distance in $L_{2}$. In contrast, the relative distance ranking is based on the distance measure in $L_{1}$. Another difference is in the calculation of the weights. TOPSIS uses the priori weights obtained beforehand by the decision-maker, while the relative distance ranking exploiting the posteriori weights obtained from the data.

For further consideration, assume that there are $q$ alternatives. Then, a multi-criteria decision analysis problem can be expressed via a trade-off matrix form as

\begin{tabular}{c|ccccc} 
& \multicolumn{7}{|c}{ Criterion } \\
Alternative & $Y_{1}$ & $Y_{2}$ & $Y_{3}$ & $\ldots$ & $Y_{m}$ \\
\hline & & & & & \\
$A_{1}$ & $Y_{11}$ & $Y_{12}$ & $Y_{13}$ & $\ldots$ & $Y_{1 m}$ \\
$A_{2}$ & $Y_{21}$ & $Y_{22}$ & $Y_{23}$ & $\ldots$ & $Y_{2 m}$ \\
$A_{3}$ & $Y_{31}$ & $Y_{32}$ & $Y_{33}$ & $\ldots$ & $Y_{3 m}$ \\
$:$ & $:$ & $:$ & $:$ & $:$ & $:$ \\
$A_{q}$ & $Y_{q 1}$ & $Y_{q 2}$ & $Y_{q 3}$ & $\ldots$ & $Y_{q m}$
\end{tabular}

where the value of $Y_{i j}$ denotes the performance of alternative $i$ in terms of criterion $j$.

\section{1 | Relative distance ranking}

In the relative distance approach, the first task is to identify the ideal solution $I^{+}$, and the anti-ideal solution $I^{-}$as follows:

$$
\begin{aligned}
& I^{+}=\left(Y_{1}^{+}, Y_{2}^{+}, \ldots, Y_{m}^{+}\right), \\
& I^{-}=\left(Y_{1}^{-}, Y_{2}^{-}, \ldots, Y_{m}^{-}\right),
\end{aligned}
$$

where

$$
\begin{aligned}
& Y_{j}^{+}=\min \left\{Y_{i j}, i=1, \ldots, q\right\}, \\
& Y_{j}^{-}=\max \left\{Y_{i j}, i=1, \ldots, q\right\},(j=1, \ldots, m) .
\end{aligned}
$$

In turn, for the maximization problem, the ideal and the anti-ideal solutions are defined as follows:

$$
\begin{aligned}
& I^{+}=\left(Y_{1}^{+}, Y_{2}^{+}, \ldots, Y_{m}^{+}\right), \\
& I^{-}=\left(Y_{1}^{-}, Y_{2}^{-}, \ldots, Y_{m}^{-}\right),
\end{aligned}
$$

where

$$
\begin{aligned}
& Y_{j}^{+}=\max \left\{Y_{i j}, i=1, \ldots, q\right\}, \\
& Y_{j}^{-}=\min \left\{Y_{i j}, i=1, \ldots, q\right\},(j=1, \ldots, m) .
\end{aligned}
$$

The other task of the algorithm is to determine the weights for each criterion. According to Kao (2010), the weightage is determined by minimizing the quadratic problem:

$$
\begin{aligned}
\text { Minimize } & \sum_{i=1}^{q}\left[\sum_{j=1}^{m} w_{j}\left|Y_{j}^{+}-Y_{i j}\right|\right]^{2} \\
\text { subject to } & \sum_{j=1}^{m} w_{j}\left|Y_{j}^{+}-Y_{j}^{-}\right|=1 \\
& w_{j}\left|Y_{j}^{+}-Y_{j}^{-}\right| \geqslant \epsilon, j=1, \ldots, m, \\
\epsilon & >0 .
\end{aligned}
$$

where $w_{j}$ is the weight or importance of an $j$-th criterion. The small quantity $\epsilon$ is suggested to avoid any criterion being neglected.

Using the weights obtained from (9), the distance of each alternative to the ideal solution and the anti-ideal solution is then calculated in $L_{1}$ by the formulae:

$$
\begin{aligned}
d R_{i}^{+} & =\sum_{j=1}^{m} w_{j}\left|Y_{j}^{+}-Y_{i j}\right|, i=1, \ldots, q \\
d R_{i}^{-} & =\sum_{j=1}^{m} w_{j}\left|Y_{j}^{-}-Y_{i j}\right|, i=1, \ldots, q .
\end{aligned}
$$

The alternative with the shortest distance to the ideal and the longest distance to the anti-ideal is ranked the highest. It is easy to prove that these alternatives coincide.

\section{2 | TOPSIS}

In TOPSIS, the first step is to standardize the data set. The step can be skip if the data are already in the standard form. The data standardization is done by the formula:

$$
r_{i j}=\frac{Y_{i j}}{\sqrt{\sum_{j=1}^{m} Y_{i j}^{2}}}, i=1, \ldots, q, j=1, \ldots, m .
$$


The next task is the data weighting process using the formula:

$$
v_{i j}=w_{j} r_{i j} \text {, where } \sum_{j=1}^{m} w_{j}=1 .
$$

As mentioned earlier, the weights for each criterion in TOPSIS method might be determined by the decision-maker. However, in the current paper, the decision-maker is not involved. Therefore, the same approach to calculate the weights as in the relative distance ranking method is imposed.

The ideal and the anti-ideal solutions in TOPSIS are then determined by

$$
\begin{aligned}
& I^{+}=\left(v_{1}^{+}, v_{2}^{+}, \ldots, v_{m}^{+}\right), \\
& I^{-}=\left(v_{1}^{-}, v_{2}^{-}, \ldots, v_{m}^{-}\right),
\end{aligned}
$$

where

$$
\begin{aligned}
v_{j}^{+} & =\min \left\{v_{i j}, i=1, \ldots, q\right\}, \\
v_{j}^{-} & =\max \left\{v_{i j}, i=1, \ldots, q\right\},(j=1, \ldots, m) .
\end{aligned}
$$

In a similar way with the relative distance approach, the ideal $I^{+}$and the anti-ideal $I^{-}$solutions are defined as reverse from the above definitions for maximization problem.

The distance from an alternative solution to the ideal solution is then calculated using the Euclidean distance as follows:

$$
d T_{i}^{+}=\sqrt{\sum_{j=1}^{m} w_{j}^{2}\left(v_{j}^{+}-v_{i j}\right)^{2}}, i=1, \ldots, q .
$$

In turn, the distance from an alternative solution to the anti-ideal solution is calculated by formula:

$$
d T_{i}^{-}=\sqrt{\sum_{j=1}^{m} w_{j}^{2}\left(v_{j}^{-}-v_{i j}\right)^{2}}, i=1, \ldots, q .
$$

As noted by Kao (2010), the TOPSIS ranking with respect to the ideal solution might be different from the ranking with respect to the anti-ideal solution.

The full ranking in TOPSIS is then expressed by formula Hwang and Yoon (1981):

$$
D_{i}^{+}=\frac{d T_{i}^{-}}{d T_{i}^{+}+d T_{i}^{-}}
$$

The largest value of $D_{i}^{+}$is accepted as the best solution, while the smallest value is regarded as the worst solution.

In the next section, the trade-off ranking approach is introduced. The method is then compared against TOPSIS and the relative distance ranking.

\section{4 | TRADE-OFF RANKING}

In this section, the key steps of the proposed method are described. The trade-off ranking is based on the property that the set of Pareto points is a set of trade-off solutions.

To demonstrate some justifications to the approach, consider a simple example with two sets of Pareto solutions, as shown in Figure 1.

The first set consists of points $\mathrm{F}, \mathrm{G}$, and $\mathrm{H}$, while the other set contains points F, I, and J. The lines FH and FJ are two different Pareto frontiers, but both contain the same point $F$ as one of the three alternatives. Consider the minimization problem. Then, the ideal solution for the example is $I^{+}=(0,0)$. The anti-ideal solution for the first set is $I^{-}=(2,4)$, and for the second set is $I^{-}=(2,5)$. In the first Pareto frontier, $\mathrm{FH}$, point $\mathrm{F}$ is the closest to the ideal solution and farthest from the anti-ideal solution. Hence, in the two ranking approaches considered above, point $\mathrm{F}$ is the most preferable solution out of the alternatives $\mathrm{G}$ and $\mathrm{H}$. Consider now another Pareto frontier, FJ. Point $\mathrm{F}$ holds the shortest distance to the ideal solution and the longest distance to the anti-ideal solution. Thus, point $\mathrm{F}$ still holds the highest ranking versus the other points I and J. As a consequence, the ranking captures the same solution regardless the entire Pareto frontier.

The key principle of the trade-off ranking is to prefer the solutions with less compromise with the others. The trade-off minimization can be achieved by calculating the distance from one point to all other points in the objective space. The distance reflects the degree of trade-off between the solutions.

The general formula for the distance between point (alternative) $A_{1}=\left(A_{1}^{(1)}, A_{2}^{(1)}, \ldots, A_{m}^{(1)}\right)$ and point $A_{2}=\left(A_{1}^{(2)}, A_{2}^{(2)}, \ldots, A_{m}^{(2)}\right)$ is

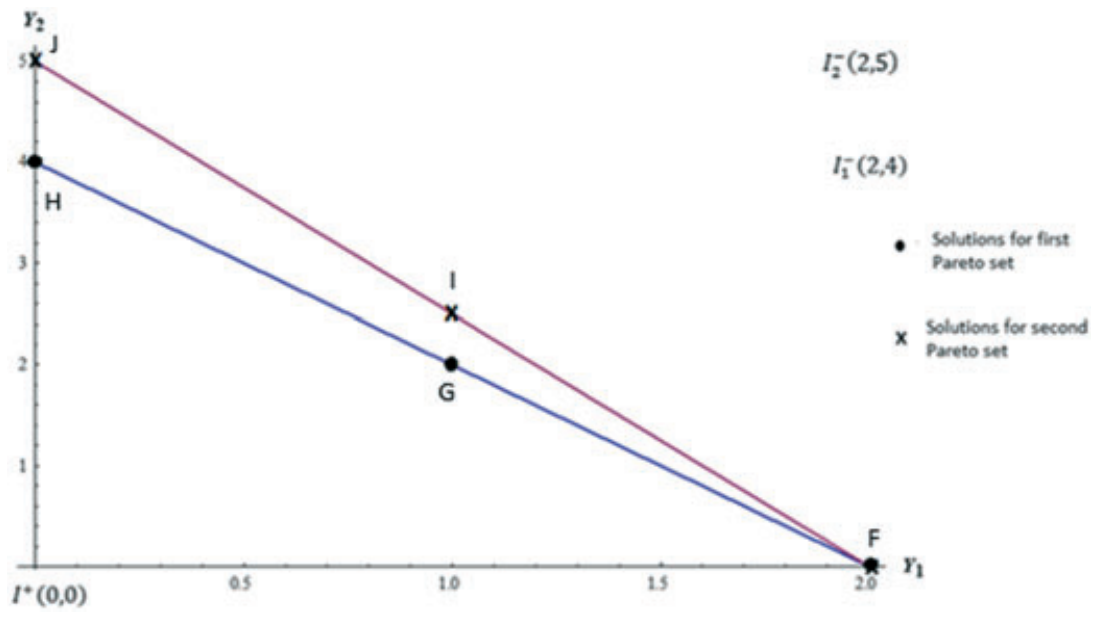

FIGURE 1 Two sets of Pareto solutions 


$$
d\left(A_{1}, A_{2}\right)=\left[\sum_{j=1}^{m}\left(A_{j}^{(1)}-A_{j}^{(2)}\right)^{2}\right]^{1 / 2}
$$

Then, the sum of distances from one point to the other points is considered as the degree of trade-off:

$$
D T_{k}=\sum_{i=1}^{q}\left[d\left(A_{k}, A_{i}\right)\right], k=1,2, \ldots, q
$$

The trade-off ranking of each solution is determined by the value of $D T$ with respect to the others. The least value of $D T$ holds the highest ranking.

For the trade-off analysis, it is efficient to have an evenly distributed set representing the entire Pareto frontier. Thus, the first step in the trade-off ranking is generating an evenly distributed Pareto set. Evenly distributed solutions give the maximum information of the Pareto frontier to the decision-maker.

As an example, consider Figure 1 again with two different sets of evenly distributed Pareto solutions $F(2,0), G(1,2), H(0,4), I(1,2.5)$, and $J(0,5)$. The results of the trade-off ranking are given in Tables 1 and 2 . In this simple example, solutions $G$ and I seem more preferable because they better represent the entire Pareto frontier. In addition, it is easy to see that they correspond to the minimized trade-off among the other Pareto solutions.

As a further justification of the methodology, consider the examples shown in Figures 2 -4.

TABLE 1 Trade-off ranking for Pareto frontier FH

\begin{tabular}{lccccc}
$\begin{array}{l}\text { Distance } \\
\text { between each } \\
\text { Pareto points }\end{array}$ & F & G & H & DT & Ranking \\
\hline F & 0 & $\sqrt{5}$ & $\sqrt{20}$ & $3 \sqrt{5}$ & 2 \\
G & $\sqrt{5}$ & 0 & $\sqrt{5}$ & $2 \sqrt{5}$ & 1 \\
H & $\sqrt{20}$ & $\sqrt{5}$ & 0 & $3 \sqrt{5}$ & 3 \\
\hline
\end{tabular}

TABLE 2 Trade-off ranking for Pareto frontier FJ

\begin{tabular}{lccccc}
$\begin{array}{l}\text { Distance } \\
\text { between each } \\
\text { Pareto points }\end{array}$ & F & I & J & DT & Ranking \\
\hline F & 0 & $\sqrt{29 / 4}$ & $\sqrt{29}$ & $\sqrt{145 / 4}$ & 2 \\
G & $\sqrt{29 / 4}$ & 0 & $\sqrt{29 / 4}$ & $\sqrt{29 / 2}$ & 1 \\
H & $\sqrt{29}$ & $\sqrt{29 / 4}$ & 0 & $\sqrt{145 / 4}$ & 3 \\
\hline
\end{tabular}

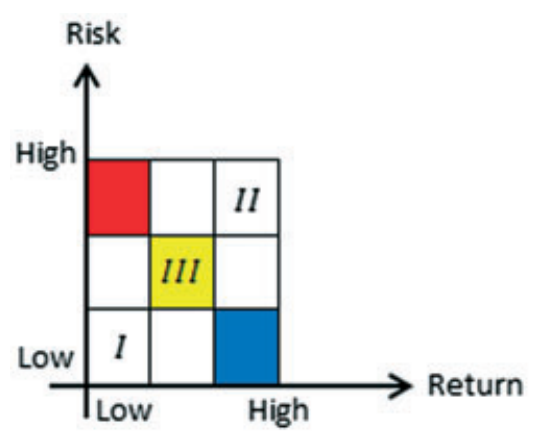

(a)

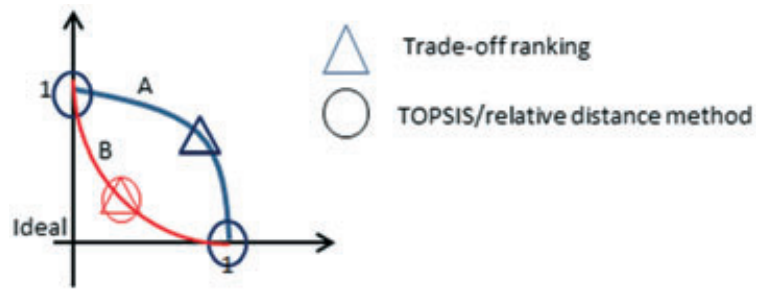

FIGURE 3 Results of the highest ranking for TNK

Figure 2 represents two different real-life trade-off problems: (a) risk over return in a share investment and (b) price over quality in a car purchase.

For a share investment, DM usually wants a low-risk investment that generates a high return. However, such a situation seems almost unrealistic. As shown in Figure 2a, investments presume possibilities I and II as the extreme options that correspond to a low risk with a low return and a high risk with a high return, respectively. Apart from these extreme solutions, there is a yellow area that gives acceptable solutions with a return higher than in I and a risk lower than in II. The trade-off ranking method interprets the best compromise solution III as the best choice.

The same situation occurs in problem (b). In case (b), it is almost impossible to buy a high-quality car with a minimal price. On the market, there is a choice in a wide range between cheap second-hand cars I and expensive luxury cars II. Many buyers prefer intermediate solutions that correspond to options in III that are cheaper than in II and of higher quality than in $I$. The trade-off ranking method can ensure that the optimal solution is in the yellow area III.

Now, to compare different approaches, in Figure 3, consider two arcs $A$ and $B$ that represent two different Pareto frontiers. In both Pareto frontiers, the top solutions for the trade-off ranking are situated in the middle of each frontier. For TOPSIS and the relative distance method, the top solutions in B are situated in the middle of the frontier as well, as they are closer to the ideal solution. However, their top solutions in A abruptly disperse between two extreme cases (areas I and II in Figure 2) as the middle area is no longer closer to the ideal solution.

Next, consider another two different graphs (a) and (b) as shown in Figure 4. In both graphs, the line $C$ is supposed to be the original Pareto frontier. In Figure 4a, as F1 changes from the original value $F 1=4$, the top solutions for TOPSIS and the relative distance approach retain. In this example, the best choice in TOPSIS and relative distance

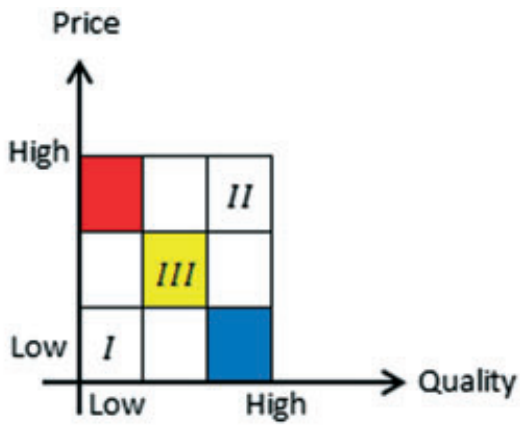

(b)

FIGURE 2 Examples for the trade-off ranking 


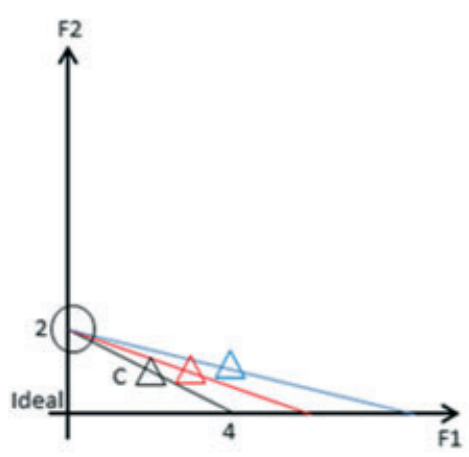

(a)

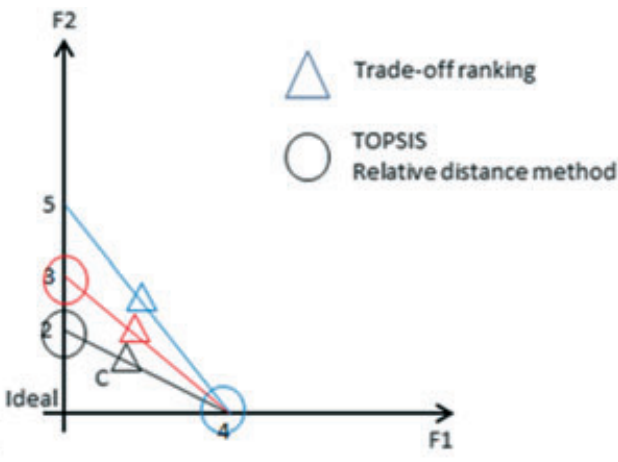

(b)

FIGURE 4 Results of the highest ranking for TNK

method might not reflect the other alternatives. For the trade-off ranking method, the top solutions change together with the new Pareto frontier while maintaining in the middle of the frontiers. In Figure $4 \mathrm{~b}$, as the value of $F 2$ changes from F2 $=2$, the top solutions for TOPSIS and the relative distance method change as well. However, the solutions correspond to the extreme cases (areas / and I/ in Figure 2). These examples demonstrate that small variations of the Pareto frontier can lead to a sharp replacement of the best choice in TOPSIS/relative distance method. For the trade-off ranking method, the top solutions retain in the middle of each frontier (area III in Figure 2).

In each example shown, the trade-off ranking method captures the best compromise solution among all alternatives provided.

In general, the steps for the trade-off ranking are as follows:

1. Generate an evenly distributed Pareto set.

2. Calculate the distance from one alternative to the others.

3. Calculate the degree of trade-off, DT.

4. Repeat steps 1 and 2 for all other alternatives from the Pareto set.

5. An alternative with less value of $D T$ holds a higher ranking.

\section{5 | TEST CASES}

In this section, the trade-off ranking is applied to seven test cases. TOPSIS and the relative distance ranking approaches are also used for a comparison. The trade-off ranking is applicable to $n$-dimensional prob- lems. The DSD approach (Erfani \& Utyuzhnikov, 2011) was used for generation of an evenly distributed Pareto set.

\section{1 | General test cases}

TNK problem: this test case is introduced by Tanaka et al. (1995). The test case considers a discontinuous Pareto frontier with significant gaps. Despite the discontinuity, DSD algorithm provides evenly distributed Pareto solutions (Erfani \& Utyuzhnikov, 2011).

$$
\begin{aligned}
& \operatorname{Minimize}\left(x_{1}, x_{2}\right) \\
& \qquad \begin{aligned}
\text { s.t.g } g_{1}(x) & =x_{1}^{2}+x_{2}^{2}-1-0.1 \cos \left(16 \tan ^{-1}\left(x_{1} / x_{2}\right)\right) \geqslant 0 \\
g_{2}(x) & =\left(x_{1}-0.5\right)^{2}+\left(x_{2}-0.5\right)^{2} \leqslant 0.5 \\
0 & \leqslant x_{i} \leqslant \pi(i=1,2)
\end{aligned}
\end{aligned}
$$

The results for the most preferable Pareto solutions identified by each method are shown in Figure 5.

For this test case, the ideal solution is $I^{+}=(0,0)$, and the anti-ideal solution is $I^{-}=(1.1,1.1)$. As can be seen in Figure 5 , the trade-off ranking approach gives preferable solutions in the middle range of both criteria $x_{1}:[0.55,0.60]$ and $x_{2}:[0.75,0.80]$. The other two methods, TOPSIS and the relative distance ranking, give the same level of ranking with much higher values for criterion $x_{2}:[0.95,1.00]$. The weights obtained in this test case are $w_{1}=0.71$ and $w_{2}=0.29$. Ten top ranked solutions for each approach are given in the Appendix.

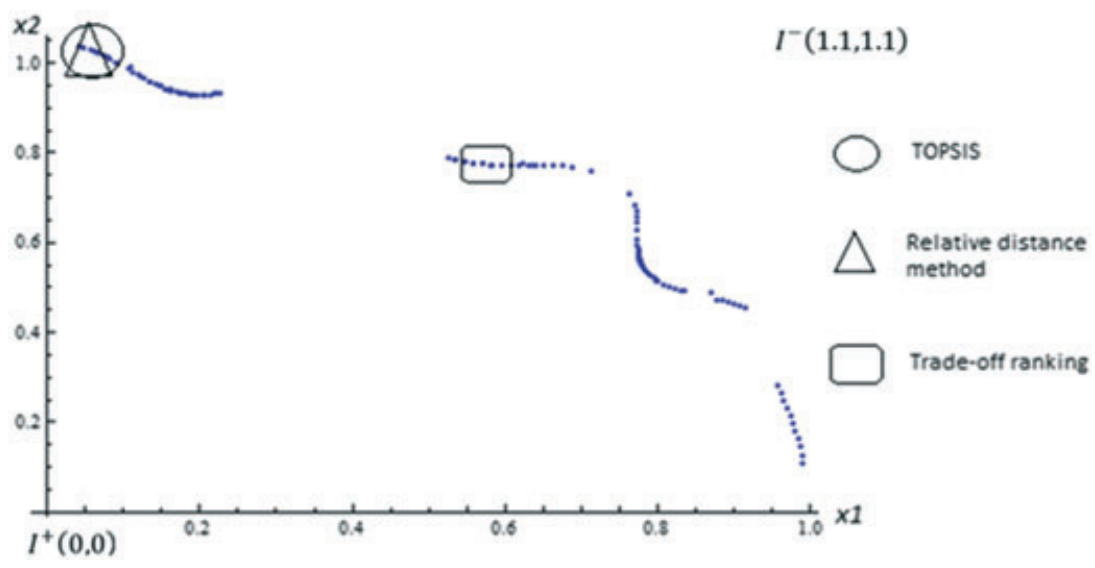

FIGURE 5 Results of the highest ranking for TNK 
ZDT1 problem: this test case is introduced by Shukla and Deb (2007). The test case has a convex Pareto optimal frontier.

$$
\begin{aligned}
& \operatorname{Minimize}\left(F_{1}(x), F_{2}(x)\right) \\
& \text { s.t. } 0 \leqslant x_{i} \leqslant 1(i=1,2, \ldots, n) \\
& \text { where } \\
& \quad F_{1}(x)=x_{1}, \\
& F_{2}(x)=g(x)\left(1-\sqrt{x_{1} / g(x)}\right), \\
& g(x)=1+9 /(n-1) \sum_{i=2}^{n} x_{i}^{2}
\end{aligned}
$$

The results of each ranking method for ZDT1 problem are shown in Figure 6.

The ideal solution for ZDT1 is $I^{+}=(0,0)$, and the anti-ideal solution is $I^{-}=(1,1)$. In Figure 6, the preferable alternatives in the trade-off ranking are in the range of $F_{1}:[0.3,0.4]$ and $F_{2}:[0.4,0.45]$. TOPSIS provides the ranking most closed to the trade-off ranking method such that highest ranking solutions are ranging from $F_{1}:[0.2,0.3]$ and $F_{2}:[0.45,0.5]$. It is worth noting that the highest ranked solution in the trade-off approach is only ranked the 13th in TOPSIS method. On the contrary, the first choice in TOPSIS is ranked the 10th in the trade-off ranking. A similar situation occurs between TOPSIS and the relative distance method. The most preferable alternative in the relative distance method is ranked the 11th in TOPSIS. The weights obtained for the ranking calculation in the relative distance method and TOPSIS are $w_{1}=0.54$ and $w_{2}=0.46$.

ZDT2 problem: this test case is introduced by Shukla and Deb (2007). The test case has a non-convex Pareto optimal frontier.

$$
\begin{aligned}
& \operatorname{Minimize}\left(F_{1}(x), F_{2}(x)\right) \\
& \text { s.t. } 0 \leqslant x_{i} \leqslant 1(i=1,2, \ldots, n)
\end{aligned}
$$

where

$$
\begin{aligned}
& F_{1}(x)=x_{1} \\
& F_{2}(x)=g(x)\left(1-\left(x_{1} / g(x)\right)^{2}\right) \\
& g(x)=1+9 /(n-1) \sum_{i=2}^{n} x_{i}^{2}
\end{aligned}
$$

The results for the best solutions for each ranking approach are shown in Figure 7.

The ideal solution for the test case is $I^{+}=(0,0)$, and the anti-ideal solution is $I^{-}=(1,1)$. As shown in Figure 7 , higher-ranking alternatives in the trade-off ranking algorithm are situated in the middle of the Pareto set within the range of $F_{1}:[0.5,0.6]$ and $F_{2}:[0.7,0.8]$. TOPSIS and the relative distance approach have the same ranking alternatives at the top rank. Both methods have the most preferable solutions in the range of $F_{1}:[0,0.1]$ and $F_{2}:[0.9,1]$. The weights obtained for ZDT2 are $w_{1}=0.69$ and $w_{2}=0.31$.

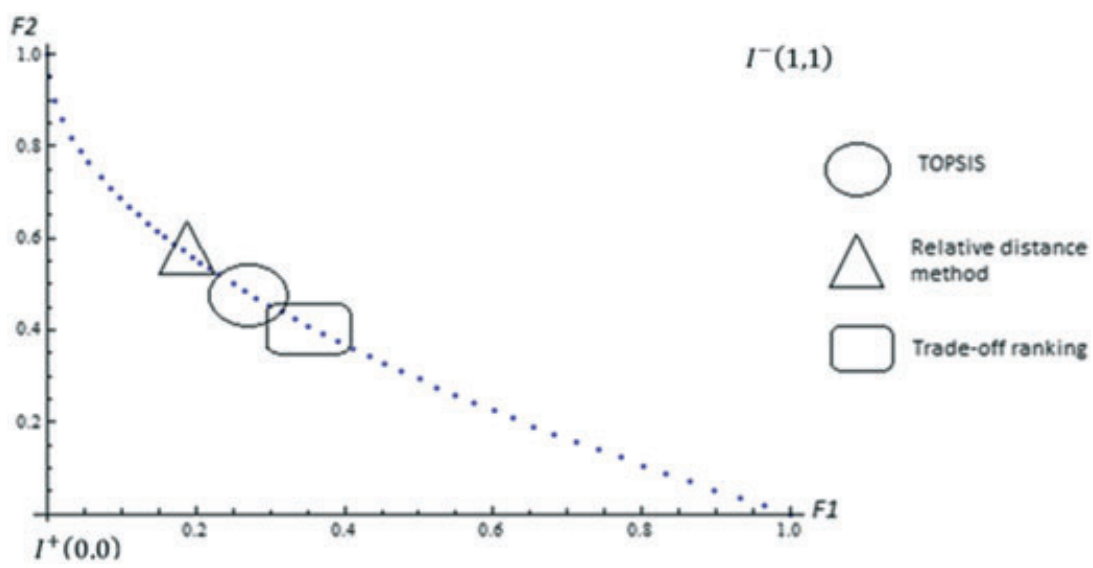

FIGURE 6 Results of the highest ranking for ZDT1

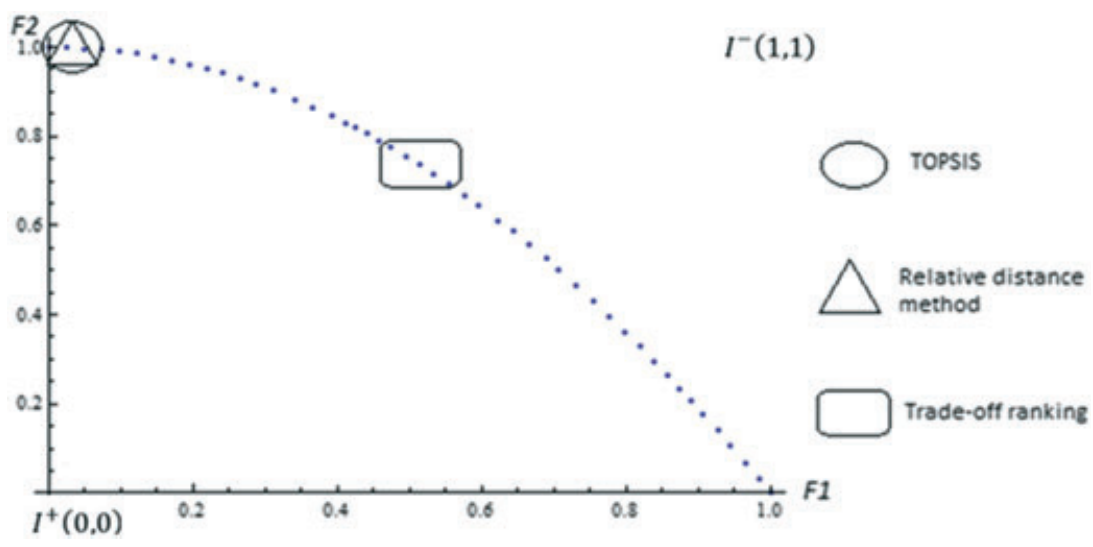

FIGURE 7 Results of the highest ranking for ZDT2 
ZDT6 problem: this test case is introduced by Shukla and Deb (2007). The test case has non-uniform density solutions on a non-convex Pareto frontier.

$$
\begin{aligned}
& \operatorname{Minimize}\left(F_{1}(x), F_{2}(x)\right) \\
& \text { s.t.0 } \leqslant x_{i} \leqslant 1(i=1,2, \ldots, 10) \\
& \text { where } \\
& F_{1}(x)=1-\exp -4 x_{1} \sin ^{6} 4 \pi x_{1}, \\
& F_{2}(x)=g(x)\left(1-\left(F_{1}(x) / g(x)\right)^{2}\right), \\
& g(x)=1+9\left(\sum_{i=2}^{10} x_{i}^{2} / 9\right)^{1 / 4}
\end{aligned}
$$

The results for the most preferable alternatives for each ranking approach are shown in Figure 8.

The ideal solution for ZDT6 is $I^{+}=(0,0)$, and the anti-ideal solution is $I^{-}=(1,0.88)$. In Figure 8 , it can be seen that the top ranked alternatives in the trade-off ranking are in the range between $F_{1}:[0.7$, $0.75]$ and $F_{2}:[0.4,0.5]$. In this test case, similar to TNK and ZDT2, the preferable alternatives in TOPSIS and the relative distance method coincide. Both methods give the alternatives with greater values for criterion $F_{1}:[0.95,1]$ and smaller values for criterion $F_{2}:[0,0.1]$. The weights for this test case are $w_{1}=0.1$ and $w_{2}=0.9$.

DTLZ5 problem: this three-dimensional test case is introduced by Deb et al. (2005). The test case has only two anchor points despite there are three-objective functions (Erfani \& Utyuzhnikov, 2011).

$\operatorname{Minimize}\left(F_{1}(x), F_{2}(x), F_{3}(x)\right)$

$$
\text { s.to } \leqslant x_{i} \leqslant 1(i=1,2,3)
$$

where

$$
\begin{aligned}
F_{1}(x) & =\left(1+g\left(x_{3}\right)\right) \cos \left(\theta_{1}\right) \cos \left(\theta_{2}\right), \\
F_{2}(x) & =\left(1+g\left(x_{3}\right)\right) \cos \left(\theta_{1}\right) \sin \left(\theta_{2}\right), \\
F_{3}(x) & =3\left(1+g\left(x_{3}\right)\right) \sin \left(\theta_{1}\right), \\
g(x) & =\left(x_{3}-0.5\right)^{2} \\
\theta_{1} & =\frac{\pi}{2}\left(x_{1}\right) \\
\theta_{2} & =\frac{\pi}{4\left(1+g\left(x_{2}\right)\right)}\left(1+3 g\left(x_{3}\right) x_{2}\right)
\end{aligned}
$$

The best alternatives for each ranking method are shown in Figure 9.

For this problem, the ideal solution is $I^{+}=(0,0,0)$, and the anti-ideal solution is $\mathrm{I}^{-}=(0.71,0.71,1)$. As shown in Figure 9 , the highest-ranking alternative in the trade-off ranking is in the middle of the set of Pareto points. TOPSIS and the relative distance method have close ranking results with greater values in the criterion $F_{3}$. The weights obtained for ranking of the relative distance method and TOPSIS are $w_{1}=0.59$, $w_{2}=0.39$, and $w_{3}=0.02$.

Comet problem: this three-dimensional test case is introduced by Deb, Thiele, Laumanns, and Zitzler (2005). The test case has a sharply shrinking Pareto optimal frontier.

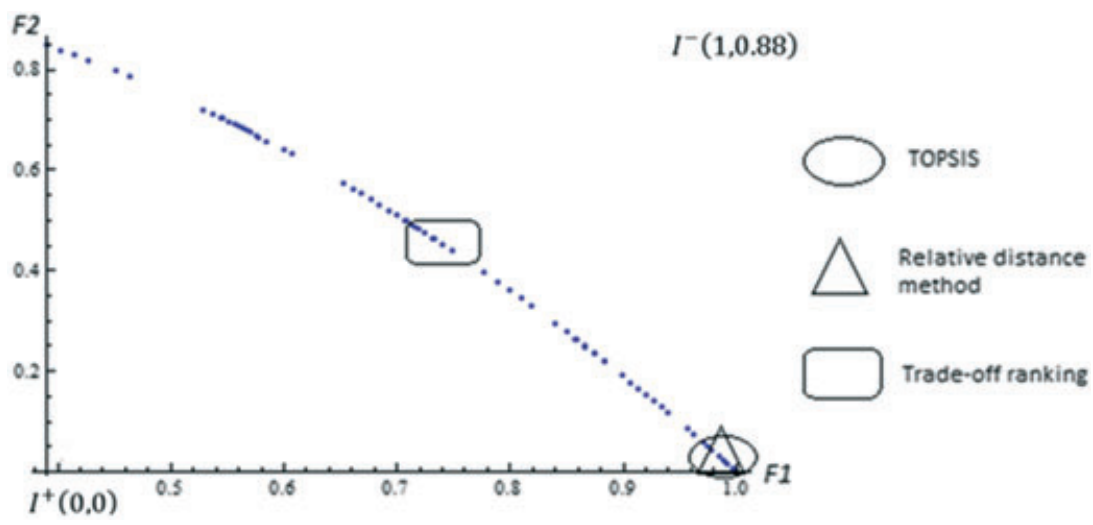

FIGURE 8 Results of the highest ranking for ZDT6

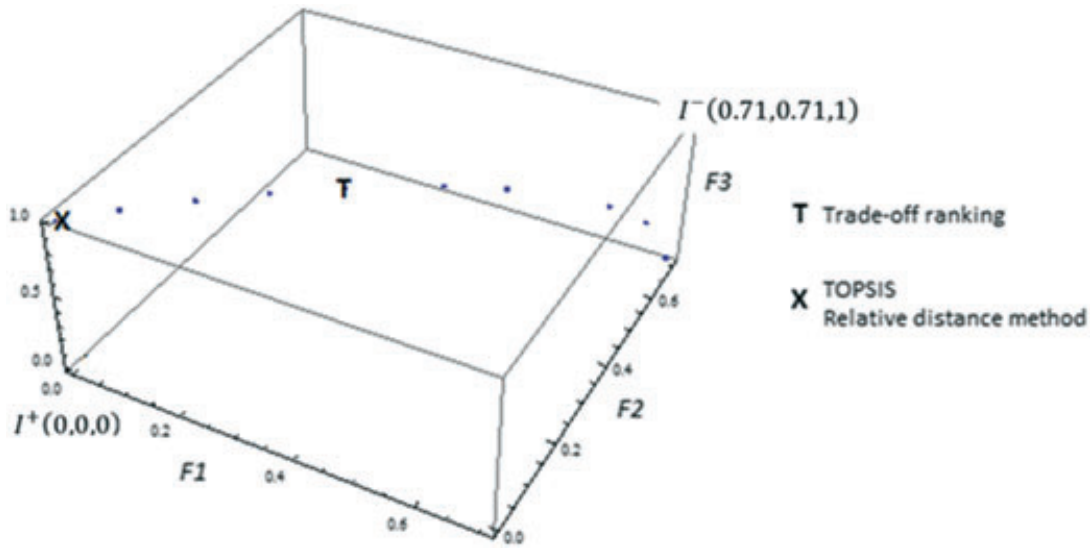

FIGURE 9 Results of the highest ranking for DTLZ5 


$$
\begin{gathered}
\operatorname{Minimize}\left(F_{1}(x), F_{2}(x), F_{3}(x)\right) \\
\text { s.t } 1 \leqslant x_{1} \leqslant 3.5 \\
-2 \leqslant x_{2} \leqslant 2 \\
0 \leqslant x_{3} \leqslant 1
\end{gathered}
$$

where

$$
\begin{aligned}
& F_{1}(x)=\left(1+g\left(x_{3}\right)\right)\left(x_{1}^{3} x_{2}^{2}-10 x_{1}-4 x_{2}\right), \\
& F_{2}(x)=\left(1+g\left(x_{3}\right)\right)\left(x_{1}^{3} x_{2}^{2}-10 x_{1}+4 x_{2}\right), \\
& F_{3}(x)=3\left(1+g\left(x_{3}\right)\right) x_{1}^{2}, \\
& g(x)=x_{3} .
\end{aligned}
$$

The results for top solutions in the comet problem are shown in Figure 10.
The ideal solution for the comet problem is $I^{+}=(-37,-36,3)$, and the anti-ideal solution is $I^{-}=(2,2,35)$. In Figure 10 , the highest ranking alternative in the trade-off ranking is situated in the middle of the Pareto set. As can be seen, TOPSIS and the relative distance method have the same level of ranking. The weights obtained for this test case are $w_{1}=0.0003, w_{2}=0.0003$, and $w_{3}=0.9994$.

\section{2 | Application test case}

Consider an example from Jacquet-Lagreze and Siskos (1982) as given in Table 3. The data correspond to 10 cars evaluated via six criteria: maximum speed, horse power, space of the car, gas consumption in town, gas consumption at $120 \mathrm{~km} / \mathrm{hr}$, and the price.

\begin{tabular}{|c|c|c|c|c|c|c|c|c|}
\hline No. & $\begin{array}{l}\text { Maximum speed } \\
(\mathrm{km} / \mathrm{hr})\end{array}$ & $\begin{array}{l}\text { Horse power } \\
\text { (CV) }\end{array}$ & $\begin{array}{l}\text { Space } \\
\left(\mathrm{m}^{2}\right)\end{array}$ & $\begin{array}{l}\text { Gas consumption in } \\
\text { town (It/100 km) }\end{array}$ & $\begin{array}{l}\text { Gas consumption at } \\
120 \mathrm{~km} / \mathrm{hr}(\mathrm{It} / 100 \mathrm{~km})\end{array}$ & $\begin{array}{c}\text { Price } \\
\text { (1000 francs) }\end{array}$ & $\begin{array}{l}\text { Trade-off } \\
\text { ranking }\end{array}$ & $\begin{array}{c}\text { Relative } \\
\text { distance ranking }\end{array}$ \\
\hline 1 & 173 & 10 & 7.88 & 11.4 & 10.01 & 49.5 & 1 & 2 \\
\hline 3 & 161 & 7 & 5.11 & 8.6 & 8.42 & 35.2 & 3 & 3 \\
\hline 4 & 148 & 7 & 6.15 & 10.5 & 9.61 & 39.15 & 4 & 7 \\
\hline 5 & 178 & 13 & 8.06 & 14.5 & 11.05 & 64.7 & 5 & 5 \\
\hline 7 & 182 & 11 & 7.81 & 12.7 & 12.26 & 68.593 & 7 & 4 \\
\hline 8 & 142 & 5 & 5.65 & 8.2 & 7.3 & 32.1 & 8 & 8 \\
\hline 9 & 180 & 13 & 8.47 & 13.6 & 10.4 & 75.7 & 9 & 6 \\
\hline 10 & 117 & 3 & 5.81 & 7.2 & 6.75 & 24.8 & 10 & 10 \\
\hline
\end{tabular}
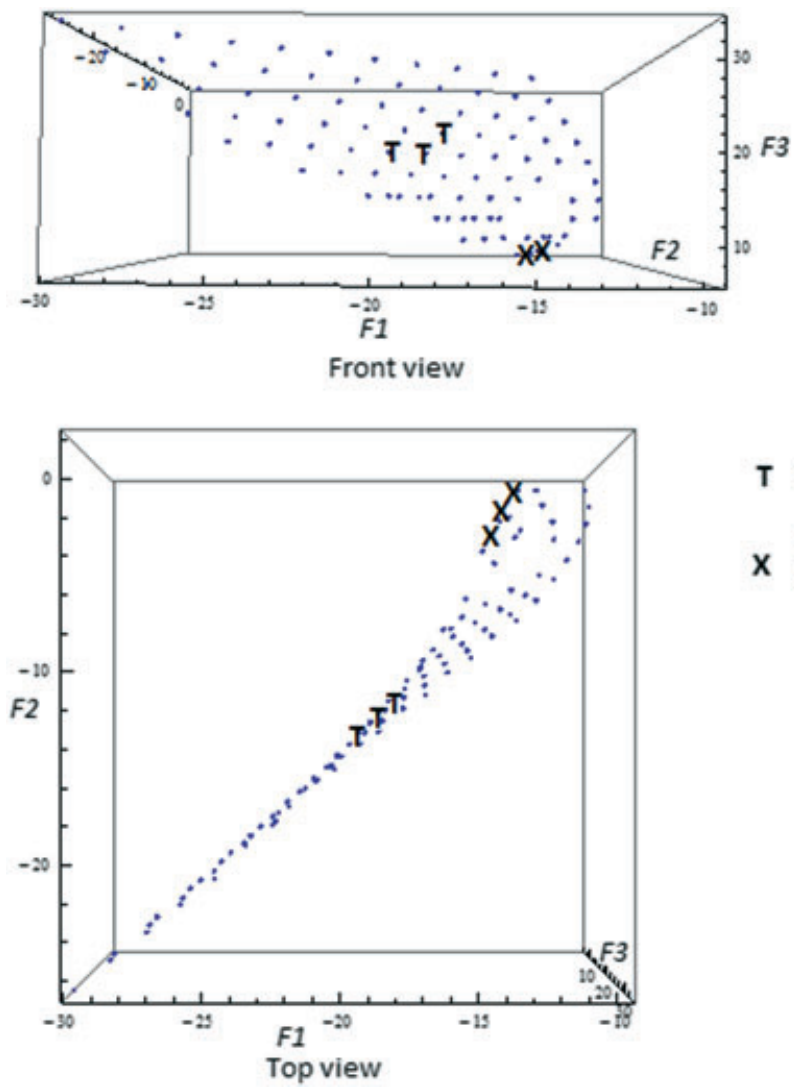

T Trade-off ranking

X TOPSIS Relative distance ranking

FIGURE 10 Results of the highest ranking for comet

TABLE 3 Input data for car selection example and the results of ranking 
TABLE 4 Preference ranking for each criterion in the car example

\begin{tabular}{lcccccccccc} 
Car no. & $\mathbf{1}$ & $\mathbf{2}$ & $\mathbf{3}$ & $\mathbf{4}$ & $\mathbf{5}$ & $\mathbf{6}$ & $\mathbf{7}$ & $\mathbf{8}$ & $\mathbf{9}$ & $\mathbf{1 0}$ \\
\hline Maximum speed & 5 & 4 & 6 & 7 & 3 & 8 & 1 & 9 & 2 & 10 \\
Horse power & 6 & 3 & 7 & 7 & 1 & 3 & 3 & 9 & 1 & 10 \\
Space & 5 & 4 & 10 & 7 & 3 & 2 & 6 & 9 & 1 & 8 \\
Gas consumption in town & 5 & 6 & 3 & 4 & 10 & 9 & 7 & 2 & 8 & 1 \\
Gas consumption at $120 \mathrm{~km} / \mathrm{hr}$ & 5 & 7 & 3 & 4 & 8 & 10 & 9 & 2 & 6 & 1 \\
Price & 6 & 5 & 3 & 4 & 8 & 7 & 9 & 2 & 10 & 1
\end{tabular}

In this example, the first three criteria (maximum speed, horse power, and space) are maximized, while the last three criteria (gas consumption in town, gas consumption at $120 \mathrm{~km} / \mathrm{hr}$, and price) are minimized. Clearly, the problem has conflicting criteria. The solutions given are the general Pareto solutions. Based on Equations (3)-(7), the ideal solution for the problem is $I^{+}=(182,13,8.47,7.2,7.3,24.8)$, while in turn, the anti-ideal solution is $I^{-}=(117,3,5.11,14.5,12.95,75.7)$. The weights $0.6346,0.01,0.01,0.01,0.01$, and 0.3254 are used for each criterion (Kao, 2010). The cars are ranked with the trade-off ranking and the relative distance ranking method. The results are shown in the last two columns in Table 3.

The rankings obtained by the relative distance method are different from those in the proposed method. The trade-off method ranks car no. 1 as the best choice, while the relative distance method ranks it as the second one. In turn, the best choice in the relative distance approach is the second in the trade-off ranking. To justify the best solution of the trade-off ranking approach in this application problem, consider Table 4.

Notice that each criterion is ranked according to its value from the input data (Table 3). The first three criteria are ranked from the highest value to the lowest value because they are the benefits criteria. It is vice versa for the last three criteria, which are ranked from the smallest value to the largest one. As can be seen in Table 4, car no.1 holds the most balanced ranking in all criteria out of the 10 cars. It is evident that the trade-off ranking approach gives the less compromise solution in comparison to the others in the general Pareto set of solutions.

\section{CONCLUSION}

A trade-off ranking approach has been proposed in this paper. The method minimizes compromise between the alternatives. The key property of the proposed approach is that in contrast to the other methods, the ranking algorithm is non-local. This means the ranking takes into account the other alternatives. It has been demonstrated that the alternative approaches can be too sensitive to small variations of the Pareto frontier. They also strongly depend on the choice of the metrics. The proposed algorithm has been tested on seven different test cases. The obtained results are compared against the rankings provided by TOPSIS and the relative distance ranking method. The trade-off ranking method selects less compromise solutions in comparison to the other techniques considered. Meanwhile, it requires the presence of a well-distributed Pareto set.

\section{ACKNOWLEDGMENT}

The first author gratefully acknowledges the research scholarship awarded by the Ministry of Higher Education Malaysia and the University of Malaysia Pahang.

\section{REFERENCES}

Ananda, J., \& Herath, G. (2005). Evaluating public risk preferences in forest land-use choices using multi-attribute utility theory. Ecological Economics, 55, 408-419.

Banar, M., Kose, B. M., Ozkan, A., \& Acar, I. P. (2007). Choosing a municipal landfill site by analytic network process. Environmental Geology, 52, 747-751.

Bascetin, A. (2007). A decision support system using analytical hierarchy process (AHP) for the optimal environmental reclamation of an open-pit mine. Environmental Geology, 52, 663-672.

Boj, J. J., Rodriguez-Rodriguez, R., \& Alfaro-Saiz, J. J. (2014). An ANPmulti-criteria-based methodology to link intangible assets and organizational performance in a balanced scorecard context. Decision Support Systems, 68, 98-110.

Brans, J., \& Vincke $P$ (1985). A preference ranking organisation method: the PROMETHEE method for MCDM. Management Science, 31(6), 647-656.

Brent, A. C., Rogers, D. E. C., Ramabitsa-Siimane, T. S. M., \& Rohwer, M. B. (2007). Application of the analytical hierarchy process to establish health care waste management systems that minimise infection risks in developing countries. European Journal of Operational Research, 181, 403-424.

Chatzimouraddis, A. I., \& Pilavachi, P. A. (2009). Technological, economic and sustainability evaluation of power plants using the analytic hierarchy process. Energy Policy, 37, 778-787.

Chen, C. T. (2000). Extensions of the TOPSIS for group decision-making under fuzzy environment. Fuzzy Sets and Systems, 114(1), 1-9.

Chen, R. Y. (2009). RFM-based eco-efficiency analysis using Takagi-Sugeno fuzzy and AHP approach. Environmental Impact Assessment Review, 29, 157-164.

Cheng, E. W. L., \& Li, H. (2007). Application of ANP in process models: An example of strategic partnering. Building and Environment, 42, 278-287.

Chu, T. C., \& Lin, Y. C. (2003). A fuzzy TOPSIS method for robot selection The International Journal of Advanced Manufacturing Technology, 21(4), 284-290.

Contreras, F., Hanaki, K., Aramaki, T., \& Connors, S. (2008). Application of analytical hierarchy process to analyze stakeholders preferences for municipal solid waste management plans, Boston, USA. Resources Conservation and Recycling, 52, 979-991.

Dabaghian, M. R., Hashemi, S. H., Ebadi, T., \& Maknoon, R. (2008). The best available technology for small electroplating plants applying analytical hierarchy process. International Journal of Environmental Science and Technology, 5, 479-484.

Das, I., \& Dennis, J. (1998). Normal-boundary intersection: A new method for generating the Pareto surface in nonlinear multicriteria optimization problems. SIAM Journal on Optimization, 8(3), 631-657.

De Leeneer, I., \& Pastijn, H. (2002). Selecting land mine detection strategies by means of outranking MCDM techniques. European Journal of Operational Research, 139, 327-338.

Deb, K., Thiele, L., Laumanns, M., \& Zitzler, E (2005). Scalable test problems for evolutionary multiobjective optimization. London: Springer.

Eckenrode, R. T. (1965). Weighting multiple criteria. Management Science, 12(3), 180-192. 
Ercanoglu, M., Kasmer, O., \& Temiz, N. (2008). Adaptation and comparison of expert opinion to analytical hierarchy process for landslide susceptibility mapping. Bulletin of Engineering Geology and the Environment, 67, 565-578.

Erfani, T., \& Utyuzhnikov, S. V. (2011). Directed search domain: A method for even generation of the Pareto frontier in multiobjective optimization. Engineering Optimization, 43(5), 467-484.

Erfani, T., Utyuzhnikov, S. V., \& Kolo, B. (2013). A modified directed search domain algorithm for multiobjective engineering and design optimization. Structural and Multidisciplinary Optimization, 48(6), 1129-1141.

Feng, C. W., Liu, L., \& Burns, S. A. (1997). Using genetic algorithms to solve construction time-cost trade-off problems. Journal of Computing in Civil Engineering, 11(3), 184-189.

Fonseca, C. M., \& Fleming, P. J. (1993). Genetic algorithms for multiobjective optimization: Formulation, discussion and generalization. International Computer Games Association, 93, 416-423.

Gomez-Navarro, T., Garcia-Melon, M., Acuna-Dutra, S., \& Diaz-Martin, D. (2009). An environmental pressure index proposal for urban development planning based on the analytic network process. Environmental Impact Assessment Review, 29, 319-329.

Goumas, M., \& Lygerou, V. (2000). An extension of the PROMETHEE method for decision making in fuzzy environment: Ranking of alternative energy exploitation projects. European Journal of Operational Research, 123, 606-613.

Gumus, A. T. (2009). Evaluation of hazardous waste transportation firms by using a two-step fuzzy-AHP and TOPSIS methodology. Expert Systems with Applications, 36, 4067-4074.

Hegazy, T. (1999). Optimization of construction time-cost trade-off analysis using genetic algorithms. Canadian Journal of Civil Engineering, 26(6), 685-697.

Herath, G. (2004). Incorporating community objectives in improved wetland management: The use of the analytic hierarchy process. Journal of Environmental Management, 70, 263-273.

Hwang, C. L., \& Yoon, K. (1981). Multiple attribute decision making: Methods and applications a state of the art survey. Berlin-Heidelberg: Sprinnger-Verlag.

Iwanejko, R. (2007). Multicriterion AHP decision-making model as a tool for supporting the selection of optimal decision in a water supply system. Environment Protection Engineering, 33, 141-146.

Jacquet-Lagreze, E., \& Siskos, J. (1982). Assessing a set of additive utility functions for multicriteria decision-making, the UTA method. European Journal of Operational Research, 10(2), 151-164.

Jahanshahloo, G. R., Lotfi, F. H., \& Izadikhah, M. (2006). An algorithmic method to extend TOPSIS for decision-making problems with interval data. Applied Mathematics and Computation, 175(2), 1375-1384.

Kablan, M. M. (2004). Decision support for energy conservation promotion An analytic hierarchy process approach. Energy Policy, 32, 1151-1158.

$\mathrm{Kao}, \mathrm{C}$. (2010). Weight determination for consistently ranking alternatives in multiple criteria decision analysis. Applied Mathematical Modelling, 34(7), 1779-1787.

Keeney, R. L., \& Raiffa, H. (1976). Decisions with multiple objectives: Preferences and value trade-Offs. New York: Wiley.

Khan, S., \& Faisal, M. N. (2008). An analytic network process model for municipal solid waste disposal options. Waste Management, 28, 1500-1508.

Kilic, H. S., Zaim, S., \& Delen, D. (2014). Development of a hybrid methodology for ERP system selection: The case of Turkish Airlines. Decision Support Systems, 66, 82-92.

Levy, J. K. (2005). Multiple criteria decision making and decision support systems for ood risk management. Stochastic Environmental Research and Risk Assessment, 19, 438-447.

Liu, C. R., Frazier, P., Kumar, L., MacGregor, C., \& Blake, N. (2006) Catchment-wide wetland assessment and prioritization using the multicriteria decision-making method TOPSIS. Environmental Management, 38, 316-326.
Messac, A., Ismail-Yahaya, A., \& Mattson, C. (2003). The normalized normal constraint method for generating the Pareto frontier. Structural and Multidisciplinary Optimization, 25(2), 86-98.

Messac, A., \& Mattson, C. (2004). Normal constraint method with guarantee of even representation of complete Pareto frontier. AIAA Journal, 42(10), 2101-2111.

Oberschmidt, J., Geldermann, J., Ludwig, J., \& Schmehl, M. (2010). Modified PROMETHEE approach for assessing energy technologies. International Journal of Energy Sector Management, 4(2), 183-212.

Petrović, M., Bojković, N., Anić, I., Stamenković, M., \& Tarle, S. P. (2014). An ELECTRE-based decision aid tool for stepwise benchmarking: An application over EU digital agenda targets. Decision Support Systems, 59, 230-241.

Randall, P., Brown, L., Deschaine, L., Dimarzio, J., Kaiser, G., \& Vierow, J. (2004). Application of the analytic hierarchy process to compare alternatives for the long-term management of surplus mercury. Journal of Environmental Management, 71, 35-43.

Saaty, T. L. (1980). The analytic hierarchy process: Planning, priority setting resources allocation. New York: McGraw.

Saaty, T. L. (1996). The analytic network process-decision making with dependence and feedback. Pittsburgh, PA: RWS Publications.

Shih, H. S., Shyur, H. J., \& Lee, E. S. (2007). An extension of TOPSIS for group decision making. Mathematical and Computer Modelling, 45(7), 801-813.

Shukla, P., \& Deb, K. (2007). On finding multiple Pareto-optimal solutions using classical and evolutionary generating methods. European Journal of Operational Research, 181(3), 1630-1652.

Soltanmohammadi, H., Osanloo, M., \& Bazzazi, A. A. (2009). Deriving preference order of post-mining land-uses through MLSA framework: Application of an outranking technique. Environmental Geology, 58, 877-888.

Srdjevic, B. (2007). Linking analytic hierarchy process and social choice methods to support group decision-making in water management. Decision Support Systems, 42, 2261-2273.

Tanaka, M., Watanabe, H., Furukawa, Y., \& Tanino, T. (1995). GA-based decision support system for multicriteria optimization. In Systems, Man and Cybernetics, 1995. Intelligent Systems for the 21st Century, IEEE International Conference, vol. 2, IEEE: Vancouver, Canada, pp. 1556-1561.

Thapa, R. B., \& Murayama, Y. (2008). Land evaluation for peri-urban agriculture using analytical hierarchical process and geographic information system techniques: A case study of Hanoi. Land Use Policy, 25, 225-239.

Tseng, M. L., Lin, Y. H., Chiu, A. S. F., \& Liao, J. C. H. (2008). Using FANP approach on selection of competitive priorities based on cleaner production implementation: A case study in PCB manufacturer. Taiwan Clean Technologies and Environmental Policy, 10, 17-29.

Utyuzhnikov, S. V., Fantini, P., \& Guenov, M. (2005). Numerical method for generating the entire Pareto frontier in multiobjective optimization. In Proceeding of Eurogen, Munich; 12-14.

Utyuzhnikov, S. V., Fantini, P., \& Guenov, M. (2009). A method for generating a well-distributed Pareto set in nonlinear multiobjective optimization. Journal of Computational and Applied Mathematics, 223(2), 820-841.

Wang, T. C., \& Chang, T. H. (2007). Application of TOPSIS in evaluating initial training aircraft under a fuzzy environment. Expert Systems with Applications, 33(4), 870-880.

Wang, Y., \& Yang, Y. (2009). Particle swarm optimization with preference order ranking for multi-objective optimization. Information Sciences, 179(12), 1944-1959.

Wu, C. R., Lin, C. T., \& Chen, H. C. (2007). Optimal selection of location for Taiwanese hospitals to ensure a competitive advantage by using the analytic hierarchy process and sensitivity analysis. Building and Environment, $42,1431-1444$.

Yong, D. (2006). Plant location selection based on fuzzy TOPSIS. The International Journal of Advanced Manufacturing Technology, 28(7-8), 839-844.

Zaidan, A. A., Zaidan, B. B., Hussain, M., Haiqi, A., Kiah, M. M., \& Abdulnabi, M. (2015). Multi-criteria analysis for OS-EMR software selection problem: A comparative study. Decision Support Systems, 78, 15-27. 
Zheng, D. X., Ng, S. T., \& Kumaraswamy, M. M. (2005). Applying Pareto ranking and niche formation to genetic algorithm-based multiobjective time-cost optimization. Journal of Construction Engineering and Management, 131(1), 81-91.

How to cite this article: Jaini N, Utyuzhnikov S. Trade-off ranking method for multi-criteria decision analysis, J Multi-Crit Decis Anal. 2016. doi:10.1002/mcda.1600

\section{APPENDIX}

Solution for TNK problem.

TABLE A1 Ranking for the trade-off method

\begin{tabular}{lcc} 
Ranking & $\boldsymbol{x}_{1}$ & $\boldsymbol{x}_{2}$ \\
\hline 1 & 0.5798 & 0.7739 \\
2 & 0.5826 & 0.7737 \\
3 & 0.5704 & 0.7747 \\
\hline 4 & 0.5692 & 0.7748 \\
\hline 5 & 0.5947 & 0.7732 \\
6 & 0.5584 & 0.7765 \\
7 & 0.5580 & 0.7766 \\
8 & 0.6065 & 0.7731 \\
9 & 0.6182 & 0.7730 \\
10 & 0.5474 & 0.7793 \\
\hline
\end{tabular}

TABLE A2 Ranking for the TOPSIS method

\begin{tabular}{lcc} 
Ranking & $\boldsymbol{x}_{\mathbf{1}}$ & $\boldsymbol{x}_{\mathbf{2}}$ \\
\hline 1 & 0.0417 & 1.0384 \\
2 & 0.0467 & 1.0358 \\
3 & 0.0480 & 1.0351 \\
\hline 4 & 0.0580 & 1.0289 \\
5 & 0.0613 & 1.0267 \\
6 & 0.0638 & 1.0249 \\
7 & 0.0678 & 1.0219 \\
8 & 0.0754 & 1.0158 \\
\hline 9 & 0.0786 & 1.0131 \\
\hline 10 & 0.0796 & 1.0123 \\
\hline
\end{tabular}

TOPSIS $=$ technique for order preference by similarity to the ideal solution.

TABLE A3 Ranking for the relative distance method

\begin{tabular}{lcc} 
Ranking & $\boldsymbol{x}_{1}$ & $\boldsymbol{x}_{2}$ \\
\hline 1 & 0.0417 & 1.0384 \\
\hline 2 & 0.0467 & 1.0358 \\
3 & 0.0480 & 1.0351 \\
4 & 0.0580 & 1.0289 \\
5 & 0.0613 & 1.0267 \\
6 & 0.0638 & 1.0249 \\
7 & 0.0678 & 1.0219 \\
8 & 0.0754 & 1.0158 \\
9 & 0.0786 & 1.0131 \\
10 & 0.0796 & 1.0123
\end{tabular}

